\title{
La TRaICIÓN EN La FICción LITERARIa. DERECHO, HECHO Y ORDALÍAS EN LA NARRATIVA Y LA EPICA EN FRANCÉS ANTIGUO ${ }^{1}$
}

\author{
por \\ STEPHEN D. WHITE \\ Emory University, Atlanta.
}

RESUMEN: A lo largo del siglo XII y comienzos del XII, muchas "chansons de geste», relatos y otras narraciones en francés antiguo producidas en Francia e Inglaterra incluian episodios en los que se resuelve un juicio por traición recurriendo a una ordalta bilateral ( $p$. e. juicio por combate, también llamado duelo judicial) o, mucho mós raramente, por medio de una ordalía unilateral (p. e. por agua fria) Alguno medievalistas han utilizado estos episodios como evidencia de que los narradores vernáculos secundaron a los clérigos en sus ataques y defensas del juicio por ordalia durante la etapa histórica en que las ordalias unilaterales estaban siendo abandonadas; con ello, han procurado integrar las fuentes literarias vernáculas en un discurso convencional sobre cómo, durante el siglo XII, el derecho irracional de la Europa altomedieval se transformó en el derecho racional de la Plena Edad Media. De la misma forma que este relato convencional del desarrollo jurídico minimiza las semejanzas entre el derecho alto y bajomedieval, también algunas recientes interpretaciones de escenas judiciales concretas en francés antiguo enmascaran continuidades significativas en este tipo de episodios, en que los mismos motivos fueron utilizados una y otra vez durante más de un siglo. Una revisión de muchos de estos juicios revela que, en las raras ocasiones en que los autores vernáculos mencionaron la ordalia unilateral, no la presentaron desfavorablemente. Aún más, estos autores trataron recurrentemente la ordalía bilateral ( $p$. e el combate) como un medio perfectamente adecuado y honorable para refutar falsas acusaciones de traición. Cuando los relatos presentan las resoluciones de algunos de estos casos imaginarios como problemáticas, atribuyen las deficiencias en los resultados alcanzados por la ordalia, no a los defectos de las ordalías como métodos de prueba, sino más bien a las dificultades inherentes a resolver problemas sustanciales sobre el derecho, la politica y el honor nobiliario, que son los que se pretende stuscitar. Al plantear estas cuestiones, las escenas judiciales de

1 Debo dar las gracias a John Hudson, Paul Hyams y Willian Miller por haberme ayndado a profundizar en varios aspectos de este trabajo.

Hispania, LVII/3, nüm. 197 (1997) 957.980 
comienzos del siglo $\mathrm{xI}$ muestran tanta sutileza y sofisticación legales como las de fines del xII y comienzos del xHI, los cuales muestran tanto interés por la cuestión de cómo negociar el honor nobitiario como los textos vemáculos de comienzos del XII.

Palabras Clave, Derecho. Inglaterra anglo-normanda. Tribunales. Sentencia. Ordalia. Litigación. Política. Violencia. Jurisprudencia

ABSTRACT: Throughout the twelfth and early thirteenth centuries, many chansons de geste, romances, and other Old French narratives produced in France and England included episodes in which the out 6 come of a treason trial is determined by means of a bilateral ordeal (i.e. trial by battle, sometimes known as a judicial duel) or, much more rarely, a unilateral ordeal (e.g. by cold water). By citing such episodes as evidence that vernacular story-tellers joined with clerics in either attacking or defending trial by ordeal during the very period when unilateral ordeals were abandoned, several medievalists have tried to incorporate vernacular literary sources into a conventional story about how, during the twelfth century, the irrational law of the early medieval Europe was transformed into the rational law of the high middle ages. Just as this conventional account of legal development minimizes the resemblances between earlier and later medieval law, so recent interpretations of selected Old French trial scenes obscure significant continuities in episodes of this kind, in which the same motifs were used and re-used for well over a century. A survey of many such trials shows that on the very rare occasions when vernacular authors mentioned the unilateral ordeal they did not represent it unfavorably. Moreover, these authors repeatedly treated the bilateral ordeal (i.e. battle) as a fully adequate and honorable means of disproving false charges of treason. To the extent that stories represent the outcomes of certain imaginary cases as being problematic, they attribute the deficiences of outcomes reached by ordeal, not to the defects of ordeals as methods of proof, but rather to the difficulties involved in resolving the substantive issues of law, politics, and aristocratic honor that the cases were constructed for the purpose of raising. In raising such issues, early twelfth-century trial scenes show as much legal subtlety and sophistication as do late twelfth-and thirteenth-century trial scenes, which reveal as much concern with the problem of negotiating aristocratic honor as do early twelfth-century vernacular texts.

Key words: Law. Disputes. Anglo-norman England. Courts. Judgment. Ordeal. Pleading. Politics. Vlolence. Jurisprudence.

Durante el siglo XII y comienzos del XIII las chansons de geste, relatos y otras narraciones en frances antiguo producidas en Francia e Inglaterra a menudo incluían episodios en los que un personaje inicia un plaid judicial, es decir, un juicio, al acusar a otro personaje de traicion. En estos episodios, los hechos narrados en otros pasajes de la misma historia se convierten en objeto de interpretaciones contrapuestas, la del acusador y la del acusado o el cam-

Hispania, LV11/3, núm. 197 (1997) 957-980 
peón del acusado, una de las cuales resulta validada, casi siempre por medio de una prueba ritualizada como una ordalía bilateral (p. e. un duelo o juicio por combate), una ordalía unilateral (p. e. por agua fría) o un juramento. Estos juicios por traición imaginarios, como a veces los he denominado, se encuentran en tantas narraciones en Francés Antiguo, ocupan lugares tan centrales en algunas historias y se asemejan tanto entre sí que parecen constituir un motivo literario reconocible que los narradores expertos sabían cómo construir e integrar en relatos más extensos y los espectadores sabían cómo interpretar. Recientemente, algunos especialistas han considerado que éstos reflejan cuál era la opinión de los autores vernáculos sobre las ordalías como medio justo de resolver las disputas en una época en que ciertas variantes de estos procedimientos estaban siendo cuestionadas.

En fecha tan temprana como 1100 ya aparece un plaid imaginario en la versión Oxford de La chanson de Roland, al describir un juicio en la corte de Carlomagno donde Ganelón es declarado traidor ${ }^{2}$. Hacia 1150, Geoffrey Gaimar incluyó un relato del juicio del earl Godwin en una historia en verso de los Ingleses, y el autor de Le roman de Thèbes incorporó a su reelaboración de la Tebaida de Estacio la narración de un debate judicial sobre la acusación de traición elevada por el rey Eteocles contra su hombre Daire el Rojo ${ }^{3}$. A partir de la década de 1170 se incluyen casos de traición en diferentes tipos de historias en Francés Antiguo ${ }^{4}$. Aparecen tanto en relatos cortos, del tipo del Lai de Lanval de María de Francia, el Amis et Amiloun anglonormando o algunas

2 La chanson de Roland, ed. WhITEHEAD, Frederick, revisada por HEMMING, T. D. (London, 1993), líneas 3698-3974 (Ganelon). Para mayor brevedad, cito cada juicio de manera completa una vez y, en adelante, me refiero a ellos simplemente citando la fuente en nota.

3 Geffrel Gaimar, L'Estoire des Engleis, ed. BeLL, Alexander, Anglo-Norman Texts, vols. 14 16, Anglo-Norman Text Society (Oxford, 1960), líneas 4895-5016 (Godwin); Le roman de Thebes, ed. y trad. Mora-Lebrun, Francine, Lettres Gothiques (Paris, 1995), líneas 8249-10,390 (Daire), que debe compararse con el juicio de La chanson d'Aspremont, ed. Brandin, Louis, 2 vols. (Paris, 1923-24), lais 313-37.

4 A la hora de localizar y analizar los juicios representados en la narrativa, incluidos algunos que no se trata aquí, son de utilidad: GUERREAU-JALABERT, Anita, Index des motifs narratifs dans les romans arthuriens francais en vers $\left(\mathrm{XII}^{\mathrm{c}}+\mathrm{XII}^{\mathrm{c}}\right.$ siecles) (Ginebra, 1992), especialmente las secciones H (Pruebas), K (Engafios), P (Sociedad), Q (Recompensas y Castigos), y S (Sociedad); y Ruck, E. H., An Index of Themes and Motifs in Twelfth-Century Arthurian Poetry (Woodbridge, Suffolk, 1991), especialmente la sección A (Law and Government: Feudal Society). Sobre duelos judiciales en obras latinas del mismo periodo, véase The Rise of Gawain, Nephew of Arthur (De Ortu Waluuanii nepotis Arturi), ed. y trad, LEAKE DAY, Mildred, Garland Library of Medieval Literature, vol. 15, serie A (New York, 1984); y The Story of Meriadoc, King of Cambria (Historia Meriadoci, Regis Cambriae), ed. y trad. LEAKE DAY, Mildred, Gariand Library of Medieval Literature, vol. 50, serie A (New York, 1988). Un caso de envenenamiento en un texto latino: Geoffrey of Monmouth, Life of Merlin (Vita Merlini), ed, y trad. Clarke, Basil (Cardiff, 1973), líneas 1401-41. Sobre una narrativa germánica medieval que representa el combate, ver CAIN VAN D'ELDEN, Stephanie, «Does Might Make Right? The Schwanritter by Konrad von Wurzburg,", en Courtly Literature: Culture and Context, ed. BUSBY, Keith y Kooper, Erik, Utrecht Pubjications in Genera! and Comparative Literature, vol. 25 (Amsterdam, 1990), págs. 549-59.

Hispanid. LVIl/3, nùm. 197 (1997) 957-980 
variantes de Le Roman de Renart, como en romances artúricos de fines del siglo XII, como Le chevalier de la charette (Lancelot) o Le chevalier au lion (Yvain) de Chrétien de Troyes, La Primera Continuación de Li conte del graal (Perceval) de Chrétien o el Roman de Tristan de Beroul s. Después de 1200, siguen apareciendo juicios por traición en muchos romans, entre ellos el Lancelot en prosa no cíclico y varias secciones del ciclo de Lancelot y el Grial (Lancelot, L'Estoire del Saint Graal, Merlin, y La mort le roi Artu) ${ }^{6}$, Florence de Rome, Florian et Florete, Durmart le Galois, Le Roman de la Rose (Guillaume de Dole) de Jean Renart, Le conte de Poitiers y Le roman de la violette de Gerbert de Montreuil ${ }^{7}$. A partir del siglo XII también destaca la presencia de juicios por traición en chansons de geste, como el Raoul de Cambrai, Ami et

5 "Lanval», en Lais de Marie de France, ed. WARNKE, Karl y trad. HARF-LANCNER, Laurence (Paris, 1990) (Lanval); Le roman de Renart, ed. y trad. DufOURNET, Jean y MEline, Andree, 2 vols. (Paris, 1985), secciones 1, 2, 5a, y 6; Chretien de Troyes, Lancelot or, The Knight of the Cart (Le Chevalier de la Charrete), ed. y trad. William W. Kibler, Garland Library of Medieval Literature [GLML], serie A, vol. 1 (New York, 1981), líneas 4737- 5053 (Meleagant); Chretien de Troyes, Le chevalier au lion, ed. F. Hult, David (Paris, 1994), líneas 3593-3765, 4312-4573 (Lunette); Beroul, The Romance of Tristan, ed. y trad. J. LACY, Norris, GLML, Ser. A, vol. 36 (New York, 1989), lineas 4116-4261 (Isolda).

h Las versiones traducidas de los juicios de Lancelot del Lago: The non-cyclic Old French Prose Romance, ed. KENNEDY, Elspeth, 2 vols. (Oxford, 1980) pueden ser localizadas convenientemente en Lancelot-Grail: The Old French Arthurian Vulgate and Post-Vulgate in Translation, ed. J. LACY, Norris, 5 vols. (New York, 1993-96): véanse los casos de Banin («Lancelot, [ Parte,» trad. N. Rosengerg, Samuel, en Lancelot-Grail, ii, 7), Pharien («Lancelot, I Parte," Lancelot-Grail, ii, 13 14), la falsa Ginebra («Lancelot, III Parte,» trad. N. RosenberG, Samuel, en Lancelot-Grail, ii, 24580), y Meleagant («Lancelot, IV Parte,» trad. L. Krueger, Roberta, en Lancelot-Grail, jii, 24-25). Ver también los casos de Marahant y Orcant («The History of the Holy Grail»» trad. J. CHAse, Carol, en Lancelot Grail, i, 151-53), la madre de Merlin («The Story of Merlin,» trad. T. PICKENS, Rupert, en Lancelot-Grail, i, 172-75), y Bertelay («The Story of Merlin,» Lancelot-Grail, i, 339-41). Sobre tres plaids incluidos en La mort le roi Artu: roman du Xu1 siecle, ed. FRAPPIER, Jean, 3.2 ed. (Paris, 1964), ver párr. 62-85 (Mador y Ginebra), párr. 90-93 (Agravain y Ginebra), y párr. 94-158 passim (Gawain y Lancelot).

7 Floriant et Florete, ed. F. Williams, Harry (Ann Arbor, 1947), líneas 4802-5507 (Maragoz); Florence de Rome, ed. WALlenskold, A., Societe des Anciens Textes Francais [SATF], 2 vols. (Paris, 1907-09), lineas 44I 1-4912 (Florence); Durmart le Galois, ed. GiLDEA, Joseph, 2 vols. (Philadelphia, 1965-66), líneas 14,103-14,766 (la reina de Irlanda y el rey Nogant); RENART, Jean, $L e$ roman de la rose or of Guillaume de Dole (Roman de la Rose ou de Guillaume de Dole), ed. y trad. PAski, Regina, GLML, vol. 92A (New York, 1995), líneas 4602-5655 (el senescal del emperador); Le conte de Poitiers, ed. Frederic Koenig, V., (Paris, 1937) (el duque de Normandia); and MontReull, Gerbert de, Le roman de la violette, ed. Labaree Buffum, Douglas, SATF (Paris, 1927), líneas 3947-4117, 5070-53332 (Euriaut). Casos adicionales en GiRART D'AMIENS, Escanor, ed. TRACHSLER, Richard, 2 vols. (Ginebra, 1994); Li Romans de Claris et Laris, ed. ALTON, Johann (1884; reimpr. Amsterdam, 1960), págs. 261, 597, 587, 661, 725; MONTREUIL, Gerbert de, La contimuation de Perceval, ed. Williams, Mary, 2 vols. (Paris, 1922-25); The Continuations of the Old French Perceval of Chretien de Troyes by Manessier, ed. RoACH, William, vol. 5 (Philadelphia, 1983). Un juicio en un relato del siglo Xv: Cleriadus et Meliadice, ed. ZıNK, Gaston (Ginebra, 1984), cc. 4,22 (Cleriadus).

Hispentia. LVIL/3, núm. 197 (1997) 957-980 
Amile, Huon de Bordeaux, Doon de la Roche, Girart de Vienne, Garin le Loheren, Gerbert, Gaydon, Gui de Bourgogne, Aye d'Avignon, Gui de Annteuil, Parise la duchesse, Tristan de Nanteuil, Macaire y La chanson de Floovant ${ }^{8}$.

Tanto en Francia como en Inglaterra, el periodo en que se compuso estos pleitos imaginarios viene marcado por cambios significativos en las prácticas judiciales, que incluyen la institucionalización de nuevos métodos probatorios y la desaparición de los antiguos desde que el IV Concilio de Letrán (1215) retiró el apoyo eclesiástico a las ordalías unilaterales ${ }^{9}$. Dado que estos cambios en el procedimiento judicial han sido a menudo relacionados con una transformación aún más amplia del derecho europeo, algunos medievalistas se han inclinado hacia la hipótesis de que el estudio de los casos legales representados en la narrativa en francés antiguo revela un cambio radical en las actitudes hacia el procedimiento judicial y el derecho. En un esfuerzo "para definir la relación entre la literatura en francés antiguo y la transformación judicial de los siglos XII y XiIn, R. Howard Bloch ha propuesto que, dado que los géneros «aristocráticos» estaban «profundamente arraigados en la evolución del ethos legal de su tiempon, la épica y la narrativa reflejaban "una crisis legal general» y, al mismo tiempo, contribuían a ella. Bloch ha asociado "esta crisis institucional y de valores" con la transición crucial de "un sistema judicial [feudal] cuya función era contener la lucha armada entre bandos privados" a un sistema judicial monárquico "adecuado para el

8 Raoul de Cambrai, ed. y trad. KAY, Sarah (Oxford, 1992), lais 227-41 (Bernier); Ami et Amile, ed. Dembowsk!, Peter (Paris, 1969), lais 73-91 (Ami y Amile); Huon de Bordeaux, ed. RuELle, Pierre, Travaux de la Faculte de Philosophie et Lettres, Universite Libre de Bruxelles, vol. 20 (Bruxelles, 1960), lais 8-17 (Huon), lais 64-66 (Agrapart); lais 85-9l (Huon y Gerard); BAR-SUR-AUBE, Bertrand de, Girart de Vienne, ed. WolfGANG VAN EMDEN, SATF (Paris, 1977), líneas 4579-5967 (Girart); Garin le Loherain, ed. VAllerie, J. E. (Ann Arbor, Ml, 1947), líneas 6213-6542 (Garin); Gerbert de Metz, ed. TAYLOR, P. (Lovaina, 1952), lais 114-23 (Fromondin); Gaydon, ed. GuESSARD, M. F., Les Anciens Poetes de la France [APF], (Reimpr. Nendeln, Liechtenstein, 1966), lineas 5891782 (Gaydon), líneas 6544-6575 (Ferraut); Aye d'Avignon, ed. BonG, S. J. (Ginebra, 1967), lais 7 23 (Garnier); Gui de Nanteuil, ed. R. MCCORMACK, James (Ginebra, 1970), líneas 219-417, 2629-2814 (Hervieu); Parise la duchesse, ed. Plouzeu, May, Senefiance, núm, 17, 2 vols. (Aix-enProvence, 1986), líneas 15-721 (Parise); Tristan de Nanteuil, ed. SiNCLAIR, K. V. (Assen, 1971), líneas 3919-4253 (Aiglentine), lineas 16800-17536 (Florine); Macaire, ed. GUESSARD, Francois, APF (Paris, 1866), págs. 32-63 (Blanchefleur), 75-107 (Macaire); La chanson de Floovant, ed. BATESON, F. H. (Loughborough, 1938), lineas 1017-1203 (Richier). Véase tambien Gui de Bourgogne, ed. Guessard, Francois and Michelant, Henri, APF (Paris, 1859); Orson de Beauvais, ed. PARIS, Gaston, SATF (Paris, 1899); y Renaut de Montauban, ed. THOMAS, Jacques (Ginebra, 1989); Doon de la Roche, ed. Meyer, Paul y HuET, Gedeon, SATF (Paris, 192l).

- Véase BALDwIN, John, «The Crisis of the Ordeal: Literature, Law, and Religion around 1200\%, Journal of Medieval and Renaissance Studies 24 (1994): 327-53; BARTLETT, Robert, Trial by Fire and Water: The Medieval Judicial Ordeal (Oxford, 1986); M. FraHER, Rjchard, «IV Lateran's Revolution in Criminal Procedure: The Birth of Inquisitio, the End of Ordeals, and Innocent II['s Vision of Ecclesiastical Politics", en Studia in honorem. . . Alphonsi M. Stickler, ed. CaStIllo Lara, Rosalino Josephus, Pontifica Studiorum Universitas Salesiana Facultas Luris Canonici. Studia et Textus Historiae Luris Canonici, vii (1992), 97-111. 
gobierno cotidiano de un dominio en pleno desarrollo" ${ }^{\circ}$. Al plantear "cuestiones de intencionalidad criminal " y "cuestionar las bases filosóficas y empiricas del combate judicial», los autores vernáculos, según Bloch, ponían de relieve tanto "la fragilidad epistemológica del procedimiento feudal» como «el fracaso de la organización feudal para hacer frente a los problemas de una era nueva, de mayor centralización" ".

Posteriormente otros medievalistas concedieron menos atención que Bloch a la transición de la justicia feudal a la justicia regia y más a la crítica de las ordalías, tratando las escenas judiciales en francés antiguo como indicios de un proceso de racionalización de los métodos probatorios medievales. Ross G. Arthur se ha basado en el análisis de la forma en que Chrétien de Troyes presenta «lo inadecuado de la prueba por combate como procedimiento judicial” para sustentar la hipótesis más general de que, si bien los «librepensadores" fueron los únicos que cuestionaron la ordalía antes de 1100, los autores vernáculos del siglo XII coincidieron en una revisión radical de este procedimiento ${ }^{12}$. A partir del análisis de una pequeña muestra de plaids imaginarios, Ronald Gene Koss ha esbozado una amplia "transformación desde la firme creencia en la equidad del veredicto derivado de un judicium $D e i$ hasta un considerable escepticismo sobre su fiabilidad como indicador de verdadera justicia» ${ }^{13}$. Recientemente John Baldwin ha utilizado algunas otras escenas judiciales para dar una vision algo distinta del fin de las ordalías. En lugar de considerar todos esos episodios como muestra de una creciente pérdida de confianza en el juicio por ordalía, Baldwin los divide entre los que apoyan este procedimiento y los que lo condenan; a continuación utiliza ambos tipos para mostrar cómo después de haber sido una institución esencial hasta fines del siglo XII, la ordalía se convirtió repentinamente en centro de una controversia en la que participaron tanto los clérigos como los autores vernáculos, y que condujo, a pesar de las resistencias, al rechazo de las ordalías unilaterales por el Concilio de Letrán en 1215 y, poco después, al abandono de las ordalfas unilaterales en los tribunales europeos ${ }^{14}$. Baldwin plantea que en una época tan tardía como la década de los 30 del siglo XIII, algunos autores vernáculos todavía defendían las ordalías como sinstrumentos de la justicia divina", mientras otros seguían criticando el procedimiento. El juicio por combate siguió en uso siglos después de 1215, pero - concluye - como

10 Howard Bloch, R., Medieval French Literature and Law (Berkeley, 1977), págs. 3, 10, 11.

1 BLoch, Medieval French Literature and Law, págs. 11, 12, 14, 18. Según Bloch, «el texto, que pretende reproducir las prácticas de la 'primera edad feudal' da constantes muestras de lo inadecuado de las mismas” (pág. 11).

12 G. ARTHUR, Ross, "The Judicium Dei in the Yvain of Chretien de Troyes," Romance Notes, xxviii (1987), 3-12, en pág. 3. Según Arthur, Chretien mostró que el duelo era "perjudicial tanto para los rectos intereses como para los mejores instintos de la nobleza feudal «(pág. 12).

13 G. Koss, Ronald, "Swindling" "justice": the judicium dei in medieval French literature," en Law and Literature in Medieval Life and Thought, ed. B. KING, Edward y J. RIDYARD, Susan (Sewanee, TN, 1990), 231-43 at pág. 231.

14 BaLDwin, "The Crisis of the Ordeal.»

Hispania, LVII/3, múm. 197 (1997) 957-980 
resultado de un debate en el que tomaron parte los autores vernáculos, «se había dado un paso significativo en la transformación del proceso judicial» ${ }^{15}$.

El efecto de estos ejercicios de innovación por parte de los medievalistas ha sido la incorporación de las fuentes literarias vernáculas a la altamente ortodoxa Historia del Derecho Medieval, donde habitualmente se representa el largo siglo XiI (ampliado hasta comienzos del XII) como escenario de la crucial transformación hacia un sistema legal racional protomoderno a partir de unas formas legales altomedievales tan irracionales y formalísticas que eran incapaces de hacer frente a problemas complejos de prueba o de intención criminal y que en las vistas no daban opción al pensamiento o la argumentación legal. Por ejemplo, Raoul C. Van Caenegem, al asociar el uso de ordalías unilaterales y bilaterales con un estadio "primitivo" del desarrollo jurídico, ha enunciado que "profundos cambios" en la estructura social y en las mentalidades produjeron "una potente corriente de modernización" que puso al descubierto lo "inadecuado" de las ordalías, las desterró y las reemplazó con "métodos probatorios más modernos» ${ }^{16}$. Con un argumento más sofisticado y especulativo, que relaciona los cambios en el procedimiento judicial y los cambios en el pensamiento jurídico, S. F. C. Milsom ha propuesto que el reemplazo de las ordalías por métodos probatorios racionales convirtió por primera vez los pleitos en escenarios para una auténtica argumentación legal. Antes de la abolición de las ordalías, «el derecho, como el hecho, estaba cómodamente arropado por el juicio de Dios: ${ }^{17}$, según Milsom, para quien el análisis detallado de los hechos fue la clave que permitió el desarrollo legal y que éste fuera tarea de juristas profesionales. "El modelo antiguo de proceso", tal y como lo denominó, tenía lugar como sigue:

El demandante formulaba su reclamación en términos formales prefijados. El demandado formulaba una refutación igualmente formal, recapitulando y denegando la acusación punto por punto. Uno de ellos juraba que su causa era justa y el juramento era examinado y puesto a prueba ... No había mucha capacidad para aceptar o rechazar pruebas, y mucho menos algo parecido a nuestra evaluación de las evidencias: el resultado del examen era concluyente. Tampoco había una ley que invocar en la sentencia. Se reconocía que el derecho estaba de parte de uno u otro y el tribunal no tenía nada más que hacer que ordenar automáticamente lo que procediese. En todo el proceso, la únicas normas sustantivas que funcionaban visiblemente eran las que estaban implícitas en el repertorio de demandas admisibles ${ }^{18}$.

15 BALDWIN, «The Crisis of the Ordeal,» pág. 353.

I6 Van CAenegem, R. C., «Methods of Proof in Western Medieval Law,» en idem, Legal History: A European Perspective (London, 1991), págs. 71-113 at págs. 73, 109-11. En «Reflexions on Rational and Irrational Modes of Proof in Medieval Europe," Tijdschrift voor Rechtsgeschiedenis, 58 (1990): $263-79$, Van Caenegem defiende su postura por medio de un ataque a los estudios más recientes sobre la ordalía.

17 MiLsom, S. F. C., Historical Foundations of the Common Law, 2nd ed. (Toronto, 1981), pags. $42-43$.

18 Mısom, Historical Foundations, págs. 38-39.

Hispunia, LV]J/3, nùm. 197 (1997) 957-980 
Por lo tanto, la sustitución de las ordalías por pruebas racionalés convirtió el plaid antiguo en un proceso judicial racional, porque «el tribunal ya no se limitaba a presidir la formulación ritual de una cuestión ante un oráculo situado por encima de toda potestad humana, sino que, al ser hasta cierto punto responsable de la respuesta, podía inclinarse a permitir al demandado apartarse de las refutaciones generales y dar su propia visión de los hechos». $\mathrm{Al}$ considerar estas licencias de los tribunales hacia los demandados como un subproducto de la sustitución de la probación irracional por la racional, Milsom subrayó la importancia de esa mutación, porque "la consideración de los hechos reales requiere la expresión, por vez primera, de normas de derechos ${ }^{19}$. Hacia 1215, como R. W. Southern ha señalado en cierta ocasión, la abolición del juicio por ordalía revela que, después de un periodo en que la gente medieval tendía a recurrir a la ordalía en cualquier caso dudoso", "se habian dado los pasos esenciales para convertir la justicia y el gobierno humanos en algo sujeto a normas humanas y dependiente de la eficacia de agentes humanos" ${ }^{20}$.

$\mathrm{Al}$ proponer, de una forma u otra, que el paso del formalismo legal ritualista al racionalismo legal humanista se puede percibir no sólo en los registros judiciales y en los escritos eclesiásticos, sino también en la literatura vernácula de los siglos XII y XIII, Bloch y sus seguidores han oscurecido algunas continuidades significativas en la historia de los juicios por traición en la literatura de este perfodo, del mismo modo que Milsom, entre otros, ha oscurecido algunas continuidades conceptuales y de procedimiento entre el derecho altomedieval y el bajomedieval. Entre 1100 y 1250 , los autores ver. náculos no produjeron innovaciones radicales ni en la materia de las acusaciones de traición que describian ni en los procedimientos judiciales seguidos para juzgarlas. Tampoco hubo cambios importantes en los modos en que dichos narradores valoraron explícita o implícitamente los métodos establecidos para resolver las disputas entre grandes nobles, que siguieron siendo a lo largo de nuestro periodo prácticamente los únicos participantes en los juicios de la ficción literaria. Caso tras caso, los tribunales de los gobernantes artúricos, carolingios o de la antigua Grecia seguían los mismos procedimientos, con los mismos protagonistas, para ver los mismos tipos de acusación sobre la traición de un noble, el homicidio o asesinato a traición, y/o la infidelidad sexual. Los personajes, que desempeñan en el juicio papeles estereotipados, argumentan sobre si el acusado habia cometido efectivamente el acto citado en la acusación de traición, sobre si el acto es realmente constitutivo de traición, y/o sobre si, en caso de ser culpable, el acusado debe ser castigado; a continuación, el tribunal casi siempre propone resolver el caso no por medio de ordalías del tipo que había sido abolido en 1215, sino

\footnotetext{
19 MLsom, Historical Foundations, pág. 43; la cursiva es adición mía. Ver otra argumentación de esta misma postura en MiLsom, S. F. C., «Law and Fact in Legal Development», en idem, Studies in the History of the Common Law (London, 1985), 171-90. $96,97$.

${ }^{20}$ SOUTHERN, R. W., The Making of the Middle Ages (1953; reimpr. New Haven, 1961), págs.

Hispania, LVI1/3, núm. 197 (1997) 957-980
} 
más bien por combate, sistema que fue perdiendo importancia práctica a partir del siglo XII, pero que los nobles siguieron apoyando, defendiendo de sus detractores y utilizando constantemente siglos después de $1215^{21}$. A la hora de resolver casos de traición que girasen en torno a cuestiones factuales claras, el duelo judicial, por más que pudiera estar sujeto a abusos ocasionales, constituía en los relatos vernáculos un modo honorable de probar o rechazar la acusación de traición y, al mismo tiempo, era una forma fiable de probar o negar los hechos. En cambio, en litigios que giraban en torno a cuestiones legales, y no meramente factuales, o bien se descartaba el duelo y se intentaba llegar a acuerdos entre los litigantes, o bien, al igual que en las escasas ordalías unilaterales de la literatura en francés antiguo, los duelos realizados servían de base para unas resoluciones de los tribunales que algunos críticos modernos han considerado problemáticas. En cualquier caso, ninguno de los dos tipos de proceso da muestras generalmente de una innovadora exclusión de las ordalías. Mucho antes de 1100, ya era una práctica común prescindir tanto de combates como de ordalías unilaterales ${ }^{22}$, de la misma manera que ya había una corriente crítica hacia las ordalías que se basaba en que podían ser manipuladas o dar pie a cualquier tipo de abuso ${ }^{23}$. En la medida en que las narraciones sobre casos problemáticos resueltos por ordalías constituían críticas implícitas de la prueba de ordalía misma, esas criticas adoptaron la forma tradicional de mostrar que ciertas disputas entre nobles debían ser resueltas por medio de acuerdos, mejor que por sentencias de cualquier tipo.

21 Véase, por ejemplo, Bartlett, Trial by Fire and Water, capítulo 6; GaUVARD, Claude, "De Grace Especial»: Crime, etat et societe en France a la fin du moyen age, 2 vols. (Paris, 1991), 1:172-79; y BILLACOIS, Francois, Le duel dans la societe francaise des XVI ${ }^{\mathrm{c}}-\mathrm{XV} \mathrm{II}^{\mathrm{c}}$ siecles: essai de psychosociologie historique (Paris, 1986), caps. 1-3. Sobre el juicio por combate en la literatura en francés antiguo, ver FauCoN, Jean-Claude, «Un curieux duel judicaire rapporte par Cuvelier», Romania 100 (1979), 382-97; Rossl, Marguerite, «Le motif du duel judicaire dans Gaydon: Traitement litteraire et signification», en Melanges de litterature du moyen age au $\mathrm{xx}^{\mathfrak{C}}$ siecle offerts a Mademoiselle Jeanne Lods, vol, 1 (Paris, 1978), págs. 531-46; Rosst, Marguerite, «Le duel judicaire dans les chansons du cycle carolingien: Structure et fonction», en La chanson de geste et le mythe Carolingien: Melanges Rene Louis, ed. BAUMGARTNER, Emmanuele, et al., vol. 2 (Saint-Pere-sousVezelay, 1982), págs. 945-60; y Rossı, Marguerite, Huon de Bordeaux el l'evolution du genre epique au $\mathrm{xur}^{\mathrm{e}}$ siecle (Paris, 1975), 223-27, 251-61, 301-15. En trabajos posteriores espero tener ocasión de comparar mi propio argumento sobre los combates y las ordalias con el de Rossí y con el que se anticipa en MicKEl, Emmanuel, «The Question of Guilt in Ami et Amile», Romania, 106 (1985): 19-35.

22 Ver Stephen WHITE, D., «Proposing the ordeal and avoiding it: strategy and power in Western French litigation», en N. Bisson, Thomas, ed., Cultures of Power: Lordship, Status, and Process in Twelfth-Century Europe (Philadelphia, 1995), 89-123.

${ }^{23}$ Ver, por ejemplo, VAN CAENEGEM, «Methods of Proof,» Se puede consultar un caso del siglo $\mathrm{XI}$ en que unos monjes se muestran preocupados por si un litigante laico pudiera estar manipulando una ordalia por medio de la magia, en BOWMAN, Jeffrey, «Law, Conflict, and Community around the Year 1000: The Settlement of Disputes in the Province of Narbonne, 985-1060» (Yale University Ph.D. thesis, 1997), cap. 4 (págs. 149-167).

Hispania, LVII/3, tมưm. 197 (1997) 957-980 
El desarrollo de los juicios imaginarios por traición no debió parecer extraño en su época a un público familiarizado con los procedimientos de los tribunales ${ }^{24}$. Pero a la altura del siglo XII, es obvio que los procesos judiciales descritos por los narradores vernáculos estaban conformados no sólo por el conocimiento de los procedimientos contemporáneos, sino también por ciertas convenciones literarias arcaizantes que los hacían inmunes frente a los cambios que estaban teniendo lugar por entonces en la práctica judicial, primero en Inglaterra y luego en Francia. En más de un aspecto, los juicios por traición imaginarios parecen más un constructo ideológico parcialmente fosilizado que un género literario realista. Desde la época del Roland de Oxford hasta el siglo XIII, un juicio de esta naturaleza tiende a desarrollarse como sigue: al tener conocimiento de un acto de traición, el señor reúne a su tribunal, donde los barones actúan como jueces. El querellante hace una acusación de traición contra el acusado y a veces se ofrece para probarla por medio de combate. A menos que la culpabilidad del acusado parezca tan obvia que el tribunal le impida defenderse y pase inmediatamente a considerar el castigo que ha de aplicarse, el acusado, o su campeón, acepta la oferta de combate del acusador o, si no se ha hecho ese ofrecimiento, propone afrontar la acusación por combate u ordalía unilateral. Los jueces discuten el caso y llegan a una primera resolución sobre la forma de prueba que se va a utilizar. Dicha prueba se efectúa y, a menos que sea cancelada para que las partes lleguen a un acuerdo, su resultado pasa a ser la base de una sentencia que bien absuelve al acusado, o bien le condena y le impone un castigo. Tal y como se representan en los libros de costumbres y en los formularios, estos procedimientos parecen descabelladamente formalistas, pero, al igual que en la práctica real de los tribunales de los siglos XI y XII, los procesos judiciales descritos en la narrativa y la épica eran flexibles. Dejaban un espacio para la discusión aparentemente impensable en el esquemático modelo de ljtigio antiguo de Milsom, pero que un autor vernáculo que escribía en fecha tan temprana como 1150 consideró verosímil y describió en detalle (Le roman de Thèbes). Los procedimientos admitían además cierto margen de maniobra política que Milsom también excluye, pero que aparece en los casos legales de la ficción literaria, como también lo haría en algunos casos históricos, a manera de continuación de la política cortesana por otros medios ${ }^{25}$.

Aunque la dinámica política del plaid literario puede variar según los casos, los personajes suelen desempeñar en esos episodios los mismos papeles prefijados: el acusador que hace su acusación por odio, envidia o despecho ${ }^{26}$;

24 Sobre la escrupulosidad con que María de Francia, por ejemplo, representa «les usages en vigeur au XII" sièclen, véase BOUTET, Dominique y STRUBEL, Armand, Litterature, politique et societe dans la France du Moyen Age (Paris, 1979), pág. 86. Baldwin señala cómo las narraciones literarias de plaids son de un realismo que las llena de verosimilitud («The Crisis of the Ordeal», pág. 333).

25 Ver R. Hyams, Paul, «Henry II and Ganelon», Syracuse Scholar, 4 (1983), 24-35.

26 Agravain y Gawain en La mort le roi Artu, los tres barones felones en ef Tristan de Beroul, el senescal de Laudine en Yvain, Meliatit en Le roman de la Violette, Amaury en Huon de Bordeaux, Thierry en Gaydon, Gawain en La mort le roi Artu.

Hispania, LVIJ/3, núm. 197 (1997) 957-980 
los acusadores estúpidos, ineptos o crédulos ${ }^{27}$; el hábil defensor ${ }^{28}$; el defensor de la dama abandonada y ultrajada ${ }^{29}$; el iracundo señor de la corte que presiona en favor de un rápido castigo para el acusado ${ }^{30}$; los barones que se unen a su señor contra el traidor denunciado ${ }^{31}$; el baron que utiliza sus conocimientos legales para interceder hábilmente en favor del acusado y que, en ocasiones, logra disuadir al señor de castigarle sin juicio ${ }^{32}$; y el caballero que se ofrece como campeón de una causa en el último momento ${ }^{33}$. Leyendo en orden cronológico los casos en que los personajes se mantienen en esos papeles, uno no llegaría nunca a apreciar que durante los siglos XII y xiII los tribunales regios, tanto en Francia como en Inglaterra, estaban realmente incrementando su poder, utilizando cada vez más las pruebas escritas, registrando una documentación cada vez más elaborada, profesionalizándose (al menos parcialmente) y desarrollando nuevos procedimientos ${ }^{34}$. Tampoco deja de ser interesante que algunos de los señores más despóticos y de los polemistas legales más hábiles aparezcan en una de las narraciones más antiguas, Le roman de Thebes.

En relación con los asuntos concretos tratados, la historia de los plaids de la ficción literaria también revela una gran continuidad. A partir del siglo XII, las acusaciones de traición repiten constantemente las mismas ofensas. Caso tras caso, se imputa al acusado haber matado a traición o haber asesinado, haber traicionado a su señor, y/o haber actuado de manera infiel al involucrarse en relaciones sexuales ilícitas. Unas formas de traición pueden entrelazarse con otras, dado que una reina que tuviera relaciones sexuales prohibidas podía ser acusada de haber traicionado a su señor y esposo, en tanto que su amante podía a veces verse acusado de traición a su señor, y dado que quien

27 El rey en Lanval, Mador de la Porte en La mort le roi Artu, Hardre en Ami et Amile, y el senescal de Ban en Lancelot.

${ }_{28}$ Ganelon en Roland, Lancelot en Le chevalier de la charette, lsolda en el Tristán de Beroul, Lancelot en La mort le roi Artu, Yvain en Le chevalier au lion, Banin en Lancelot, y Lienor en Guillaume de Dole.

29 Isolda en el Tristán de Beroul, Florence en Florence de Rome, Parise en Parise la duchesse, Olive en Doon de la Roche, Euriaut en Le roman de la violette, and Ginebra en La mort le roi Artu.

30 Carlotnagno en Roland, Eteocles en Le Roman de Thebes, el rey en Lanval, Isolda en el Tristân de Beroul, Carlomagno en Amis et Amilun y Ami et Amile, y Arturo en el segundo proceso a Ginebra en La mort le roi Artu.

31 Ver Le roman de Thebes, Lanval, algunas variantes de Le roman de Renart, La mort le roi Artu, y Le roman de la Violette.

32 Othon en Le roman de Thebes, el duque de Cornwall en Lanval, Dinas en el Tristán de Beroul, y el señor de Aspremont en Le roman de la violette.

33 Y vain (dos veces) en Yvain, Lancelot en La mort le roi Arru, Gerart en Le roman de la Violette, y Thierry en Roland.

${ }^{34}$ Sobre los tribunales de justicia ingleses y franceses, ver, respectivamente, Hudson, John, The Formation of the English Common Law: Law and Society in England from the Norman Conquest to Magna Carta (London, 1996), caps. 5 6; y W. BALDwiN, John, "The Capetian Court at Work under Philip Augustus», en The Medieval Court in Europe, ed. R. HAYMEs, Edward, Houston German Studies, ed. R. HAYMEs, Edward, vol. 6 (1986), págs. 71-91.

Hispania, LVIJ/3, nủm. 197 (1997) 957-980 
matase a un hombre de su señor podía ser acusado de traicionar a éste. Las acusaciones por traición al señor son corrientes a lo largo de todo el período ${ }^{35}$, como lo son las de homicidio a traición ${ }^{36}$. En otras acusaciones las relaciones sexuales prohibidas representan unas veces una forma de de traición o deslealtad al esposo de la amante y otras simplemente una mala acción ${ }^{37}$.

Mientras que en el modelo de litigio antiguo de Milsom los acusados solo están autorizados a responder a tales acusaciones por medio de refutaciones formales, los acusados en los juicios por traicion imaginarios tienen otras

35 Carlomagno acusa inicialmente a Ganelón de haber traicionado a los doce pares por dinero; y luego Thierry le acusa de haber traicionado a Roldán, perjudicado a Carlomagno, cometido perjurio y quebrantado la fidelidad (Roland). El rey Eteocles acusa a Daire el Rojo de traición por intentar entregar una torre a Polinices, el enemigo de Eteocles (Le roman de Thebes). El senescal de Laudine imputa a Lunette haber traicionado a Laudine por Yvain (Yvain). Roldán acusa a Girart de Vienne de quebrantar la fidelidad a su sentor Carlomagno (Girart de Vienne). Bernard de Naisil acusa a Garin le Loherain de planear matar al rey Pipino (Garin le Loherain). Amaugin le Brun acusa a Garnier de Nanteuil de planear matar a Carlomagno (Aye d'Avignon). Carlomagno, secundado por otro Thierry, acusa a Gaydon (antes Thierry) de planear matar al emperador con fruta envenenada y haber matado accidentalmente a un hombre del emperador (Gaydon). Huon acusa a su propio hermano de haberle traicionado (Huon de Bordeaux). Banin acusa al senescal de Ban de ser «un traidor que ha traicionado tanto a Dios como a su señor natural en la tierra «; posteriormente, un caballero anónimo del rey Claudas se ofrece a probar que Pharian traicionó al rey al albergar a los hijos del enemigo mortal de Claudas. En el mismo relato una mujer que pretende ser Ginebra acusa a Arturo y a todos sus barones de tratarla con deslealtad al desterrarla, deheredarla y reemplazarla por una impostora (Lancelot). Sobre algunos de estos casos véase la obra de Rossi antes ciłada en la nota 21 y A. Dessau «L'idee de la trahison au Moyen Age et son role dans la motivation de quelques chansons de geste," Cahiers de civilisation medievale, 9 (1960), 23-36.

36 Mador de la Porte acusa a Ginebra de matar a traición a su hermano Gaheris; posteriomente Gawain acusa a Lancelot de matar a traición a sus hermanos (La mort le roi Artu). Amaury jura que Huton asesinó al hijo de Carlomagno; más adelante en el mismo relato, el gigante Agrapart acusa a Huon de asesinar a su hermano (Huon de Bordeaux). Euriaut es acusada de asesinar a la hermana del duque (Le roman de la violette). Gautier acusa a Bernier de haber matado con felonía al señor natural de Bernier, Raoul, tío de Gautier (Raoul de Cambrai). Gerbert imputa a Fromont haber matado a traición a su padre, Garin le Loherain (Gerbert). Floriant acusa al senescal Maragoz de haber asesinado al rey Elyadus de Sicilia durante una cacería (Floriant et Florete). Hervieu acusa a Gui de haber matado a traición a su padre, Milon (Gui de Nanteuil). Aumaugin acusa a Parise de haber envenenado al hermano de su esposo (Parise la duchesse). Aiglentine es acusada de asesinato por el principe sarraceno Galafre (Tristan de Nanteuil). El duque Emelon de Bavaria denuncia que su hijo fue asesinado por Richier (La chanson de Floovant). Gui jura que Ferraut asesinó a un centinela (Gaydon).

37 Agravain acusa a Ginebra de haber cometido «una gran deslealtad» al permitir que «un caballero diferente del más noble de los reyes yaciese con elta" (La mort le roi Artu). Lanval se ve acusado de avergonzar al rey al solicitando el amor de la reina (Lanval). Hardre jura que habia sorprendido a Belissant y a «la persona cuya mano tomo en la mía» abrazados, totalmente desnudos, como marido y mujer (Ami et Amile). Según la acusación de Meleagant, cel senescal Kay pasó esta noche con la reina y disfrutó plenamente de ellan (Chretien, Lancelot). La acusación que Arturo aconseja a Isolda que refute es la de que el amor de Tristán hacia ella fuese "corrupto o carnal» (Beroul, Tristan). En un tipo de proceso distinto, Lienor se queja de que el senescal del emperador Conrado le arrebató su virginidad (Guillaume de Dole).

Hispania, LVII/3, núm. 197 (1997) 957-980 
opciones, incluso en los textos épicos más primitivos. Ya se trate de una acusación de asesinato, traición al señor o sexo ilícito, el acusado o su campeón puede hacerle frente por medio de lo que se denomina una refutación general, declarando falsa la acusación sin indicar por qué lo es; también puede hacer una alegación para explicar por qué el acusado no ha obrado mal; o puede pronunciar un juramento de negación que es en sí ambiguro y explota la ambigüedad de la acusación. Estas alegaciones pueden tomar tres formas diferentes. A veces los acusados o sus campeones juran, efectivamente, que toda la acusación tergiversa los hechos ocurridos porque el acusado no realizó el acto traicionero que el acusador invoca ${ }^{38}$. El acusado o su campeón puede también alegar que la acusación incluye al menos un error material, tergiversación, malinterpretación u omisión de importancia decisiva acerca de las circunstancias en que el acusado había llevado a cabo el acto que se le imputa y que, de hecho, sí realizó. Este tipo de alegación la usan, por ejemplo, acusados que dicen que mataron en defensa propia, no a traición, o que dicen que una acción que se imputa como traicionera no lo fue realmente ${ }^{39}$. Un tercer tipo de alegación implica afirmar que la denuncia por traición malinterpreta las intenciones del acusado al hacer algo que se le acusa de haber hecho y que, en efecto, hizo ${ }^{40}$. A veces no es fácil distinguir claramente esta estrategia de defensa de la estrategia de negar que un acto supuestamente traicionero fuese realmente traicionero ${ }^{41}$. Otro método de afrontar una acu-

38 Lanval, en respuesta al cargo de que al requerir el amor de la reina hubiese actuado de forma vil y deshonrosa y cometido «felonía» hacia el rey, dice que no había buscado el amor de la reina (Lanval). Cuando Meleagant jura que Kay gozó de Ja reina esa noche, Lancelot responde jurando que Kay «jamás durmió con la reina ni la tocó» (Chretien, Lancelot). Cuando Lienor disfrazada acusa al senescal del emperador de «haberle arrebatado su virginidad y haberle robado su cinturón, bolsa y brochen, los amigos del senescal defienden a éste diciendo que probará por ordalía de agua fría que «que nadie hasta hoy ha puesto sus ojos sobre ella, ni (...) tocado su piel desnuda; no recibió de él daño alguno» (Guillaume de Dole).

39 La defensa de Huon contra el cargo de asesinato presentado por Amaury no es que él no hubiese matado a Charlot, hijo del emperador, sino más bien que hasta mucho después de hacerlo no supo quien era su víctima y que lo mató en defensa de su propia vida (Huon de Bordeaux). Daire arguye que, a pesar de haber cometido de hecho una acción que podría haber sido traicionera en cierto contexto, las circunstancias en que obró no permitían considerarlo así (Le roman de Thebes). Bernier usa una estrategia similar para responder al cargo de haber matado a traición y con felonía a Raoul de Cambrai, su señor natural (Raoul de Cambrai).

40 La defensa de Lancelot frente al cargo de Mador de que Ginebra había matado al hermano de éste a traición es que la reina no planeaba cometer una traición (La mort). Yvain defínde a Lunette del cargo de haber traicionado a su señora por él aduciendo que ella no tenía intención de traicionar (Chretien's Yvain).

41 Ganelon responde a la acusación de Carlomagno de haber traicionado a los doce pares por dinero aduciendo que se tomó venganza, pero no cometió traición (Roland). Para refutar que Pharian hubiese traicionado al rey Claudas por albergar a los hijos del rey Bors, el sobrino de Pharian dice: «puede haberles dado cobijo, pero eso no significa que cometiera traición hacia ti. (...) porque mi tío no hizo sino cumplir su juramento de fidelidad al rey Bors. Incluso a pesar del mal trato recibido de su señor, tiene el deber de proteger a sus hijos jgual que lo haría su propio señor, si estuviera vivo aúns (Lancelot-Grail).

Hispania, LVIl/3, nu்m. 197 (1997) 957-980 
sación de traición es hacer una refutación general, que por fuerza resulta ambigua, ya que siempre se puede imaginar más de un motivo para declarar falsa la acusación ${ }^{42}$. Finalmente, otras estrategias más evasivas para defenderse de las acusaciones incluyen juramentos ambiguos, a veces acompañados de disfraz o suplantación ${ }^{43}$. Aunque los juramentos de negación ambiguos cobran significados diferentes en diferentes narraciones, habitualmente permiten al acusado o a su campeón responder a una acusación que hubiera sido dificil (aunque no necesariamente imposible) refutar sin perjurio ${ }^{44}$.

El estudio de estas acusaciones y defensas muestra que los narradores

42 Después de que Ganelón formule su alegación a la acusación de Carlomagno, Thierry reformula la acusación y Pinabel, campeón del primero, responde simplemente diciendo: «declaro que es fatso» (Roland). Justo antes de su batalla con Gawain, Lancelot responde al cargo de haber matado a traición al hermano de aquél dando a Arturo la representación para defenderle (La mort le roi Artu). El senescal de Ban hace la misma defensa ante la acusación de Banin de que el senescal había traicionado a su señor natural y perjurado (Lancelot-Grail).

43. En lugar de seguir el consejo de Arturo y negar que el amor de Tristán por ella fuese «corrupto o carnal», Isolda jura que «ningún hombre ha estado jarnás entre mis piernas, con la excepción del leproso que (...) cargó conmigo para cruzar el vado y mi esposo, el rey Mark». Puesto que el teproso en cuestión era en realidad Tristán, cuyo amor por Isolda podía ser considerado en una cierta interpretación si no corrupto, al menos carnal, lsolda evita el perjurio y logra su propósito de refutar por medio de un juramento la acusación de haber tenido relaciones sexuales ilícitas (Beroul, Tristón). En Ami et Amile, Amile saca partido de la vaguedad de la acusación de Hardre: relaciones ilícitas entre Belissant y la persona cuya mano Hardre sostiene, pero cuyo nombre no llega a pronunciar. Jura que él, Amile nunca había yacido con Belissant ni sentido el contacto de su piel. Puesto que Amile suplantaba a su doble Ami, quién sí habia tenido relaciones con Belissant, puede negar la acusación de Hardre sin perjurio (Ami et Amile). En una de las historias de Renard, Hersent niega haber tenido relaciones con Renard jurando, primero, que éste no le había hecho a ella nada que no haría a su propia madre y, después, que ella misma no había obrado de forma más concupiscente que lo hubiera hecho una monja (Le roman de Renart, variante l).

44 En Guillaume de Dole un juramento de negación ambiguo sirve a un propósito distinto cuando los amigos del pérfido senescal del emperador sugieren que el senescal pruebe por ordalía de agua fría ( $¿$ por qué no un duelo?) que nunca había visto anteriormente a su acusadora y que nunca habia tocado su piel destuda o le había hecho daño alguno. Aquí, la ambigüedad del juramento reside en el hecho de que la acusadora del senescal no es la mujer que él cree. Al verse acusado de arrebatar la virginidad de la mujer y robar su cinturón, bolsa y broche, el senescal piensa que, aunque todos los presentes vean que él lleva puesto el mismo cinturón que describe la demandante, puede negar el cargo sin faltar a la verdad porque piensa que nunca ha visto antes a esa mujer y que el cinturón que lleva es regalo de otra. Sin embargo, dado que el senescal es víctima de un complot, el juramento se presta a un interpretación radicalmente distinta de la qué el pretende. Al ser la demandante en realidad Lienor, cuya virginidad él se ha jactado anteriormente de haber tomado, su juramento de negación constituye el reconocimiento de que él no ha tomado su virginidad. Un instante después, Lienor, disfrazada, formula una oración ambigua, pidiendo a Dios que obre un milagro que demuestre que «ella no se merecia la pérdida que tuvo que sufrir». Mientras el senescal y cualquiera de los presentes tienen motivos para pensar que la pérdida aludida es la virginidad de la acusadora del senescal, así como el broche, la bolsa y el cinturón, la pérdida en que ella piensa es el honor que ella y su familia perdieron cuando el senescal declaró haber tomado su virginidad.

Hispuinio, LVII/3, nủm. 197 (1997) 957-980 
familiares que combinaron y recombinaron y transmitieron a sus sucesores ${ }^{45}$. Además de los personajes tópicos mencionados más arriba, entre los participantes en los plaids se incluyen, como acusados, el barón que ayuda al enemigo de su señor ${ }^{46}$, o que perjudica de cualquier otra manera a su señor y sus amigos ${ }^{47}$, el caballero que mata sin reconocer a su víctima ${ }^{48}$, el caballero que mata en defensa propia ${ }^{49}$, el caballero que mata a una persona distinta de la que pretendía matar ${ }^{50}$, y la reina o dama acusada falsamente y/o a traición de faltar a la castidad ${ }^{51}$. Además de los acusadores airados y/o crédulos ya citados, también encontramos como denunciantes en plaids imaginarios al pretendiente rechazado que se venga de quien le desairó acusándole de traición ${ }^{52}$ y al traidor que intenta culpar a otro de sus propias fechorías ${ }^{53}$. Entre las víctimas de homicidios se cuentan los hombres envenenados y los muertos durante una cacería ${ }^{54}$.

Al integrarse estos personajes y motivos tópicos en el grueso de la narración, uno de los episodios de ésta pasa a ser objeto de interpretaciones opuestas en el plaid, que se convierte así en escenario de una discusión entre personajes sobre si el acusado había realizado realmente la acción traicionera denunciada por el acusador o si el acto merecía ese calificativo ${ }^{55}$. Algunos

45 Para consultar ejemplos de este proceso, ver ANNE CAMPBELL, Kimberlee, The Protean Text: A Study of the Versions of the Medieval Legend of "Doon and Olive» (New York, 1988); PLouzEAu, May, «Introduction», in Parise la duchesse, ed. Plouzeau, págs. 129-59.

A6 Ganelon in Roland, Daire le Roux in Le roman de Thebes, el senescal de Ban y Pharien en el Lancelot en prosa.

47 Lancelot en La mort le roi Artu.

48 Lancelot en La mort le roi Artu, Huon en Huon de Bordeaux.

49 Huon en Huon de Bordeatx, Richier en La chanson de Floovant.

50 Avarlan en La mort le roi Artu, Meliatir en Le roman de la Violette, Thierry en Gaydon.

sI Parise en Parise la duchesse, Olive en Doon de la Roche, Isolda en el Tristán de Beroul, Ginebra en el Lancelot de Chretien y en La mort le roi Artu. Ver BUHRER-THIERRY, Genevieve, "La reine adultere», en Cahiers de civilisation medievale, 35 (1992): 299-312; y MCCRACKEN, Peggy, "The Body Politic and the Queen's Adulterous Body in French Romance", en Feminist Approaches to the Body in Medieval Literature, ed. LOMPERIS, Linda y STANBURY, Sarah (Philadelphia, 1993), 38-64.

52 Meliatir en Le roman de la Violelte, la reina en Lanval.

53. Avarlan en La mort le roi Artu, Thierry en Gaydon.

s4 Gaheris en La mort le roi Artu, el squire de Carlomagno en Gaydon. Garin en Garin le Loherain, el rey de Sicilia en Floriant el Florete, cuyo editor cita nueve narraciones o textos épicos en francés antiguo en los que la caza es el escenario de un asesinato (pág. 27).

ss Cuando los barones de Cariomagno cuentan al emperador lo que creen que se deberia hacer con Ganelón, él los llama «felones»; Thierry entonces interpreta ta ofensa de Ganelón en términos significativamente diferentes de los empleados por Carlomagno (Roland). En el juicio de Lanval los barones expresan tres opiniones diferentes sobre cómo se le debería tratar (Lanval). En el juicio de Euriaut, dos señores debaten sobre cómo debería proceder el tribunal (Le roman de la violette). En el juicio de Huon, el abad de Cluny apoya a éste contra su acusador; posteriormente, Naimes discute un asunto de procedimiento con Carlomagno (Huon de Bordeaux). La acusación de traición de Gawain contra Lancelot no sólo es discutida por Lancelot y su parentela, sino también por el aliado de Gawain, Yvain; Arturo se opone al plan de Gawain de probar su versión por medio de un combate con

Hikpania, LVII/3, nüm. 197 (1997) 957-980 
casos incluso están construidos para suscitar la cuestión de si un acusador que sea traidor él mismo está legitimado para avergonzar a otro noble probando públicamente que sea un traidor. Lo que se discute, en otras palabras, son cuestiones factuales, cuestiones legales y cuestiones sobre el honor y la deshonra. Para algunos participantes en los plaids, igual que para el público, que ya estaba familiarizado con los hechos anteriormente narrados, las respuestas a la cuestiones factuales eran obvias ${ }^{56}$, pero las cuestiones legales y de honor eran más discutibles, como muestran a las claras tanto los debates entre los personajes de estas historias como las discusiones entre los modernos estudiosos en publicaciones académicas ${ }^{57}$. Algunos juicios imaginarios por traición plantean mayores dificultades acerca de la intención del acusado, si lo que hizo lo hizo a traición, y si, independientemente de lo que hubiera hecho o pretendido hacer, merecía ser deshonrado públicamente como traidor. En vez de documentar un brusco descubrimiento, propio de fines del siglo XII, de la intencionalidad como materia legal, la historia de los plaids imaginarios muestra que la cuestión es tan antigua como el propio género. En Roland, la cuestión de si Ganelón cometió traición o se vengó justamente de los barones a los que había desafiado previamente se construye a veces como una indagación sobre sus intenciones ${ }^{58}$. El extenso proceso de Daire el Rojo, de mediados del siglo xII, plantea problemas de intencionalidad en un caso que está construido ex profeso para plantearlas, junto con otras muchas cuestiones sobre la traición ${ }^{59}$. Es cierto que en los juicios de la literatura de

Lancelot. El envenenamiento de Gaheris es objeto de varias interpretaciones y, en momentos diferentes, es presentado de manera distinta por distintos personajes ( $L a$ mort). Aunque Othon refuta, a la larga, las acusaciones de Eteocles contra Daire, todos los restantes consejeros del rey -Sicart, Salin, Alis, y Creon- le apoyan, mientras que la madre del rey, Yocasta, ofrece otra opinión sobre cómo resolver el caso (Roman de Thebes). La cuestión de cómo proceder contra Renard es debatida, en una ocasión, por Bruin el oso, Bruyant el toro, el tejón y Bemard el asno; en otra ocasión, el debate incluye un camello italiano, Baucent el jabali, Brichemer el ciervo, Bruin el oso, y Platel el venado (Le roman de Renart, versiones $1 .^{a}$ y $5{ }^{\text {a }}$ ). Los amigos del senescal del emperador Otto le defienden acusando a su desconocido acusador de practicar la magia (Guillaume de Dole). Los tribunales también debaten asuntos como si el acusado está habilitado para defenderse y qué modo de prueba debería usarse.

${ }_{56}$ Aunque en "Lanval» el rey sostiene que Lanval le había avergonzado y envilecido, el público sabe que Lanval tiene razón cuando niega «punto por punto haber ofendido y avergonzado a su señon porque, dice, «él no había buscado el amor de la reinas (Lanval). De forma similar, el público sabe que en Huon de Bordeatx, Hugh es falsamente acusado de haber matado a Charlot y que en $L e$ roman de la Violette, Euriaut es falsamente acusada de haber matado a Ysmaine.

57 Ver, por ejemplo, el debate entre Lynette Muir and R. Howard Bloch: MuIR, Lynnette, «Further Thoughts on the 'Mort Artu', I," Modern Language Review, 71 (1976), 26-28; HowARD BLOCH, R., «Further Thoughts on the "Mort Artu", II," Modern Language Review, 71 (1976), 28-30. El articulo de Muir responde a HowaRD BLOCH, R., «From Grail Quest to Inquest: The Death of King Arthur and the Birth of France», Modern Language Review, 69 (1974), 40-55.

58 ¿Traicionó a los pares «por aveir», como alega Carlomagno, o tan sólo buscaba una guerre abierta con ellos? ¿Traicionó a Carlomagno, como alega Thierry, o se mantuvo leal a él, según sostiene el propio Gawain y tal y como implica la refutación general de Pinabel (Roland)?

59 Ver D. White, Stephen, «Legal Puzzles in Old French Romances and Epics: The Case of Gawain v. Lancelot,» Haskins Society Joumal (en prenșa).

Hispania, LVII/3, núm. 197 (1997) 957.980 
ficción de los años 70 del siglo XII y posteriores, las cuestiones sobre la culpabilidad de acusados que causaron un daño sin pretender necesariamente que éste fuera el que citan sus acusadores se argumentan de forma más precisa que a comienzos del siglo XII, pero las cuestiones no son completamente nuevas ${ }^{60}$.

Desde los juicios más antiguos en Roland y Le roman de Thèbes hasta los más tardíos del Lancelot en prosa y de La mort le roi Artu, los tribunales plantean cuestiones legales normativas sobre qué es la traición y quién debe ser públicamente deshonrado como traidor. ¿Se puede acusar a un hombre de traicionar a otro a quien ha desafiado previamente ${ }^{61} 0$ a quien tenía buenas razones para desafiar ${ }^{62}$ ? Desafiar a alguien antes de matarle ¿exonera al homicida de la culpabilidad por esa muerte ${ }^{63}$ ? ¿Puede uno traicionar a su señor sin saberlo o sin pretenderlo ${ }^{64}$ ? ¿Puede un caballero matar a traición si ignora la identidad de su víctima y, de conocerla, no la hubiera matado ${ }^{65}$ ? ¿Es siempre la defensa propia una excusa aceptable ante una acusación de asesinato ${ }^{66}$ ? ${ }^{2}$ Puede un hombre matar de forma descubierta y que, sin embargo, el acto constituya una traición ${ }^{67}$ ? ¿Es traidor el que da cobijo a los herederos menores de su difunto señor, si éste era enemigo mortal de su señor actual? ${ }^{68}$. También se suscitan cuestiones de debate en juicios imaginarios en los que el propio acusador es un traidor y/o acusa por envidia, odio o despecho o en los que un acusador con razones para querer vengar su propia deshonra efectúa una acusación imprecisa y viciada. También suscitan la polémica los casos en

\footnotetext{
60 Algunos otros casos están diseñados para suscitar la cuestión de cuándo las relaciones sexuales ilícitas constituyen o no verdadera traición, o, por decirlo de otra forma, de si los amantes adúlteros deben ser públicamente infamados como traidores. Inmediatamente después de que los barones de Arturo sentencien que Ginebra «debería morir de forma infamante, por haber cometido una acción verdaderamente desleal al permitir que un caballero distinto del más noble de los teyes durmiese con ella», Gawain señala a la sentencia en sí misma como una «atrocidad». En tanto que Afturo dictarnina que «la hoguera es la única muerte apropiada para quién ha cometido traición», el pueblo de Camelot achaca la muerte de ella a la «deslealtad» de Arturo y declara que «los traidores responsables de esto deberán morir con deshonray. Anteriormente, Arturo mismo propone la siguiente defensa ante la acusación de Agravain de que «Lancelot ama pecaminosamente a la reina, y ella a él»: «Estoy seguro de que Lancelot jamás pensaria siquiera en cosa semejante; e incluso si lo hiciera, sería por la futerza del amor, contra la cual nada pueden el juicio y la razón» (LancelotGrail). La narración del encuentro sexual entre Amile y Belissant muestra que el primero, o bien ignoraba quién era ella o bien cuidó de que pareciera que pensaba que se trataba de una sirvienta (Ami et Amile). Tristán dice que está dispuesto a luchar para negar que «haya amado a la reina de modo pérfido y prohibidom: La acusación es, por supuesto, ambigua (Tristán de Beroul).

${ }_{61}$ Roland, Raoul de Cambrai.

62 Le roman de Thebes.

his La mort le roi Antu.

64 Lunette en Yyain.

os La mort le roi Arru, Huon de Bordeawx.

to Huon de Bordeaux.

67 La mort le roi Artu, Huon de Bordeaux.

is Caso de Pharian en el Lancelot en prosa.
} 
que el campeón del acusado está implicado en su traición o en los que el acusado pronuncia un juramento deliberadamente ambiguo. Incluso si un juramento de acusación insidioso resulta ser cierto, ¿no está corrompido por la traición? ¿está su autor legitimado para deshonrar al acusado llamándole traidor públicamente y demostrarlo por medio de un combate? Un asunto diferente es el que suscitan los litigios en que un acusador cegado por la ira, o simplemente mal informado, formula incorrectamente una acusación que podría haber resultado válida ${ }^{69}$. ¿Debe perder el caso sólo por haber errado en su precipitación? A la inversa, uno puede preguntarse, como hacen los críticos modernos, si debería ser absuelto quien refuta una acusación aparentemente verdadera de relaciones sexuales ilícitas por medio de un juramento deliberadamente ambiguo ${ }^{70} \mathrm{o}$ si un acusado podría ser absuelto gracias al esfuerzo de un campeón que puede ser a su vez el culpable de la ofensa que se imputa al acusado 7 .

Al intentar resolver casos de traición que suscitan cuestiones normativas y factuales de esta naturaleza, los tribunales presentados por los narradores vernáculos tienen la opción de permitir al acusado afrontar una ordalía unilateral o permitir a las dos partes o a sus campeones enfrentarse en duelo. El señor de la corte judicial también tiene la opción de rechazar las razones de las partes que desean entablar combate ${ }^{72}$, y otras veces las partes se acogen a la opción de detener un duelo y alcanzar un acuerdo. Un recorrido por los juicios imaginarios revela que las ordalías unilaterales se aplicaban tan raramente que es difícil creer que los narradores vernáculos como grupo estuviesen implicados activamente en el debate sobre este procedimiento. Si contamos los juramentos exculpatorios como ordalías unilaterales, el Tristan de Beroul proporciona un ejemplo de este proceso. Si asumimos que en el Tristan original de Thomas, tal y como figura en su traducción al noruego antiguo, Isolda probaba su inocencia afrontando una ordalía de hierro candente, ahí tendríamos un segundo ejemplo de una ordalía unilateral consumada ${ }^{73}$. Puesto que no hay ejemplos de juicios consumados por agua hirviente y sólo uno de ordalía por agua fría ${ }^{74}$, parece que en el período en que supuestamente los narradores se unieron a los clérigos en la crítica contra la ordalía unilateral, sólo algunos estuvieron siquiera en en situación para hacerlo. Uno de estos autores narró un juramento, no una completa ordalía y el tratamiento de la ordalía que hizo el otro no se conserva para ser analizado

\footnotetext{
69 Mador y Gawain en La mort le roi Artu.

70 Tristán de Beroul; Ami et Amile.

21 En el Lancelot y el Wuain de CHRETJEN.

72 Gawain y Lancelot en La mort le roi Artu.

73 Saga af Tristram og Isond, ed, OlASON, Vesteinn (Reyk- javik, 1987), cc. 56-60 (págs. 99 105); para una traducción al francés moderno, ver Tristan et Iseut: Les poemes francais, La saga norroise, trad. LACroIx, Daniel and WALTER, Philippe, cc. 56-60 (págs. 574-79). Merece destacarse que el juicio por combate aparece presentado en tn tono claramente favorable en algunas versiones đe la historia de Tristán.

74 Guillaume de Dole.

Hispania, LVIJ/3, núm. 197 (1997) 957-980
} 
en su lengua original. Para ser exactos, quienes proponen las ordalías unilaterales son diferentes mujeres acusadas ${ }^{75}$, pero todas esas propuestas, al igual que otras muchas efectuadas en casos reales durante los dos siglos anteriores, no llegan a nada, puesto que la disputa se resuelve finalmente por medio de un combate.

Si la cuestión es proporcionar a un tribunal argumentos para emitir un juicio justo en una demanda que gira en torno a una simple cuestión factual, el combate funciona bien en los juicios de la ficción literaria; y también el juicio por agua fría cumple su cometido en el caso en que se utiliza ${ }^{76}$. En unos pocos casos, el duelo no desemboca en una resolución justa porque o bien se interrumpe el combate, o un contendiente cobarde abandona, o bien se desarrolla de manera inadecuada ${ }^{77}$. Y en un plaid tras otro, el vencedor del combate es aquel cuyo juramento se ajusta a los hechos, tal y como éstos han sido presentados previamente al público. Aunque hay un caso en que el acusador prueba su juramento por medio de la lucha ${ }^{78}$, generalmente el duelo funciona en los pleitos de la ficción como el instrumento ideal para que los nobles respondan a acusaciones falsas lanzadas contra ellos o contra damas que puedan encontrar caballeros que luchen por su causa ${ }^{79}$. Dada la frecuencia con que

\footnotetext{
75 Euriaut en Le roman de la Violette, Constance en Constance de Rome, y Olive en Doon de la Roche.

76 El resultado de una ordalía de agua fría revela correctamente que el senescal del emperador Contado no era culpable de una ofensa que se le había imputado falsamente (Guillaume de Dole).

7 Cuando Gerbert está a punto de probar que Fromont es un traidor matando a su campeón Fromondin, Fromondin es rescatado por Guillaume de Monclin y una partida de caballeros (Gerbert). El rey Nogant acuerda enfrentarse en duelo a Durmart en caso de que éste sea un rey, no un simple principe. Pero cuando el padre de Durmart habilita a su hijo para cumplir esa condición al darle el reino de Dinamarca, el rey Nogant se escabulle (Durmart le Gallois). Después de que Amauri acusa falsamente a Huon de haber asesinado a Charlot, Huon le derrota y le obliga a confesar; pero en vista de que nadie escuha la confesión, Carlomagno contraviene la costumbre y el consejo de Naimes desterrando a Huon de todas formas (Huon de Bordeaux).

78 Caso de Pharien en el Lancelot en prosa.

79 Cuando Bernard de Naisi] acusa falsamente a Garin de planear matar al rey Pipino, Begón, campeón de Garin mata al campeón de Bernard, Isore (Garin le Loherain). Acusado falsamente de planear matar a Carlomagno, Gaydon derrota al traidor Thierry en combate (Gaydon); y al derrotar a Gui, Ferraut prueba que mató a un centinela en defensa propia, en lugar de asesinarie (Gaydon). En un duelo con el gigante Agrapart, Huon prueba que no mató al hermano del gigante (Huon de Bordeaux). Después de lidiar con el pérfido senescal Maragoz, Floriant le obliga a confesar que mató al rey de Sicilia (Floriant et Florete). Cuando Auboin acusa falsamente a Garnier de Nanteuil de planear matar a Carlomagno, Gamier vence a Auboin en combate y le obliga a confesar su perjurio (Aye d'Avignon). Cuando Gui de Nanteull es falsamente acusado de matar a Milon, vence y mata a Hervieu (Gui de Nanteuil); como secuela de esta historia, el príncipe sarraceno Galafre acusa falsamente a Aiglentine de asesinato, pero acaba confesándose su autor al ser derrotado por Gui en duelo (Tristan de Nanteuil). Al ser Florine falsamente acusada de traición, Doon la defiende en combate con éxito (Tristan de Nanteuil). Ante la falsa acusación de haber asesinado al hijo del duque de Baviera, Richier vence al duque en combate, y con ello demuestra que mató en defensa propia ( $L a$ chanson de Floovant). Cuando Thomas de l'Angarde acusa falsamente a Cleriadus y Meliadice de traición, Cleriadus vence en duelo a Thomas, quien confiesa su mentira (Cleriadus er Meliaduce).
} 
el duelo resulta efectivo para probar hechos, no es sorprendente encontrarlo explícitamente representado como un método justo para determinar qué parte en un juicio por traición imaginario tiene razón y cuál no y merece un castigo. Para escenificar la idea de que un caballero débil que tenga razón puede derrotär a uno fuerte que no la tenga, varias historias destacan la desventaja en fuerza y experiencia que el campeón de la verdad ha de superar ${ }^{80}$ (Roland, Huon de Bordeaux). El Roland de Oxford resume la muerte de Thierry por Pinabel declarando que Dios había hecho un milagro. Al advertirle el principal acusador de Lunette que defender la causa de ésta contra tres caballeros sería descabellado, Yvain responde: "Creo enteramente todo lo que ella me ha dicho, y la defenderé si puedo porque mi fuerza reside en su rectitud (droit). Y, si es cierto lo que se dice, Dios mismo se pone de parte de quien obra rectamente, y Dios y la rectitud (droit) son una misma cosa; y puesto que están de mi lado, por eso tengo mejores compañeros que tú y mejores seguidores ${ }^{81}$ ». Cuando un mensajero le insta a no enfrentarse a Lancelot en duelo, Gawain contesta:

"Si la verdad (droit) no estuviese tan obviamente de mi parte, no lucharia [con Lancelot] ni por la mayor ciudad del mundo, porque sé (...) que es el mejor caballero que he conocido jamás. Pero todos saben que la maldad y la deslealtad convierten en malhechor al mejor de los caballeros y que la rectitud y la lealtad convierten al peor en seguro y valiente. Por eso temo menos a Lancelot, porque sé que el está en el error y yo en la verdad. De manera que ni tú ni otros debéis temer por mí, porque en todas partes Nuestro Señor está de parte del bien; esa es mi esperanza y mi fés ${ }^{82}$.

Gawain pierde su combate con Lancelot, pero no simplemente porque Lancelot fuera un caballero más fuerte, sino porque Gawain, como más tarde reconoce, no tenía razón ${ }^{83}$.

Aunque los resultados de otros casos librados por ordalía unilateral o bilateral son discutibles y no resuelven necesariamente de modo satisfactorio todos los problemas que el caso en cuestión suscita, la producción de plaids imaginarios no debería ser considerada como indicio de intento alguno de criticar o cuestionar lo que Bloch llama genéricamente «las bases empíricas y filosóficas" tanto del combate como de las ordalías unilaterales.

Por contraste con algunos clérigos detractores de las ordalías, los autores vernáculos, tal y como señala Baldwin, nunca describieron un proceso en el

\footnotetext{
Al derrotar al duque de Normandía en combate, el conde de Poitiers prueba que su esposa es leal y el duque perjuro (Le conte de Poitiers). En una historia que fue reelaborada en diferentes lenguas durante siglos, la esposa de Carlomagno, Blancaflor es falsamente acusada de haber tenido relaciones sexuales con un enano y es defendida en combate por un fiel perro que obliga al acusador de la reina, Macaire, a confesar públicamente su perjurio (Macaire).

80 Roland, Huon de Bordeaux.

81 Yvain.

82 Lancelot-Grail. 4:138.

83 Ver White, «Legal Puzzles.»
}

Hispunia, LVIL/3, nủm. 197 (1997) 957-980 
que una ordalía unilateral o un duelo sirva para dar validez a un juramento literalmente falso ${ }^{84}$. Mas aún, en casos en que a partir de duelos u ordalías unilaterales se toman resoluciones discutibles, los argumentos en favor de la resolución parecen ser más fuertes que los opuestos a ella, especialmente si estos juicios de ficción se entienden más como contiendas entre nobles sobre el honor que como mecanismos para gobernar un reino aplicando leyes a situaciones de hecho y castigando a los que violan el derecho. Por ejemplo, aunque el duelo entre Thierry y Pinabel no proporciona ninguna respuesta concluyente a las cuestiones de traición que el caso de Ganelón suscita, justifica que se dé como sentencia que un barón que ha deshonrado a su señor fanfarroneando sobre su traición merece una muerte deshonrosa y que es legítimo que el señor que sufrió esa deshonra se vengue y aplaque su ira descuartizando al traidor y ahorcando a sus garantes ${ }^{85}$.

Aunque, obviamente, el juramento ambiguo que Isolda utiliza para librarse del cargo de que el amor de Tristán hacia ella fuese corrupto y carnal no revela nada definitivo sobre lo acertado de esa acusación, cumple simultáneamente con un doble proposito: en primer lugar, librar a un acusado de un juicio que tanto Arturo corno el senescal de Mark consideran insólito y, en segundo, deshonrar a los enemigos felones. Además tanto Isolda como Tristán posiblemente podrían haber defendido su amor usando el argumento que Arturo, en La mort le roi Artu, propone a Lancelot como defensa contra la acusación de Agravain de que "Lancelot ama pecaminosamente a la reina, y ella a él»: "Estoy seguro de que Lancelot jamás pensaría siquiera en algo así; e incluso si lo hiciera, sería por la fuerza del amor, contra el cual son impotentes el juicio y la razón" ${ }^{86}$.

Es inapropiado comparar implícitamente y en términos desfavorables los juicios emanados de ordalías unilaterales o bilaterales con los resultados que podrían haberse alcanzado por otros medios, como los procesos judiciales

84 Según Baldwin, una de las quejas de Pedro el Cantor hacia las ordalías era que «las ordalías frecuentemente fracasan, porque condenan al inocente y dejan libre al culpable» («The Crisis of the Ordeal», pág. 340). No obstante, según Bartlett, estas quejas eran relativamente raras y tenían mucho menos peso que el argumento de que «dicha práctica era indeseable ... por ser anticanónica y por tentar a Dios" (Trial by Fire and Water, pág. 81).

85 Roland.

${ }^{86}$ Lancelot-Grail, 4:92. Para ser exactos, la sentencia basada en la victoria de Lancelot sobre Mador no da lugar a venganza o compensación por la muerte de Gaheris y nunca plantea la cuestión de si Ginebra albergó alguna intención de matarle. Pero el combate muestra que, dado que Ginebra no estaba pensando en cometer una traición cuando dió ạ hermano de Mador lo que resultó ser una fruta envenenada, no le mató a traición y no merecía moris por ese infortunio. Además, Mador merece ser deshonrado, primero por hacer una acusación sesgada basada en noticias de otros y después, por no ser capaz de superar la ingeniosa defensa de Lancelot ( $L a$ mort le roi Arfu). Incluso a pesar de que la victoria final de Lancelot en duelo sobre Gawain deja la puerta abierta a la cuestión de si habría incurrido en alguna responsabilidad por las muertes de Gaheriet y Agravain, él ciertamente no mató a los hermanos de Gawain a traición y sale del gran enfrentamiento contra Arturo con más honor que Gawain, quien tras sufrir una herida mortal en su combate con Lancelot, le pide a este perdón por haberle tratado vilmente y reconoce que muere por su propia neceḍad (La mort le roi Artu). 
basados en pruebas racionales, como pesquisas o juicios por jurado. Los narradores jamás mencionaron estas pruebas, y mucho menos las trataron como racionales, y en consecuencia preferibles a los combates, que siguieron siendo para los nobles el método de prueba preferido en casos de traición. Mas aún, ¿qué utilidad podría haber tenido un método de prueba racional en procesos cuyos casos más interesantes y complejos están construidos para plantear cuestiones acerca de la traición, el derecho y el honor, en vez de asuntos que se puedan resolver por medio de la investigación de los hechos? Simplemente no hay prueba alguna que sustente la hipótesis de que los autores vernáculos estuviesen mostrando una preferencia por los métodos racionales frente a los irracionales al imaginar juicios en los cuales las resoluciones, casi siempre derivadas de duelos, no zanjan completa y efectivamente las disputas. Nada permite sostener que un tribunal provisto de un jurado o de procedimientos inquisitivos pudiese haber respondido a las cuestiones suscitadas por juicios imaginarios mejor que los tribunales de la ficción usando el juicio por combate. ¿Podría una pesquisa o un jurado haber dirimido cuestiones como estas:? ¿Debería ser Isolda condenada a muerte basándose en las acusaciones de unos barones notoriamente felones y de un enano insidioso, a través de un procedimiento judicial que el rey Arturo califica de atrocidad ${ }^{87}$ ? ¿Debería Ginebra ser ejecutada como consecuencia de un juicio que Agravain forjó movido por la envidia y el despecho, y que Gawain considera atroz y el pueblo de Camelot condena como traicionero ${ }^{88}$ ¿ ¿De qué hubieran servido mejores métodos de investigación de los hechos en el caso de Daire el Rojo, que suscitaba cuestiones de derecho, política y honor, y no meramente factuales ${ }^{89}$ ?

Los autores vernáculos a veces indicaron que lo único preferible a un juicio basado en el resultado de un duelo o una ordalía bilateral sería un acuerdo del tipo que se alcanza en el caso de Daire, en algunos otros juicios imaginarios, y en un número significativo de casos históricos que se remontan al

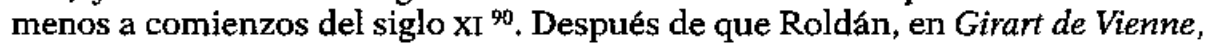
acuse a Girart de haber quebrantado su fidelidad hacia Carlomagno, Oliveros desafía a Roldán y se ofrece para luchar con él en nombre de Girart. Los esfuerzos para reconciliar a los litigantes fracasan y se entabla el combate, pero Dios interviene, deteniendo la lucha y envolviendo a los dos contendientes en una espesa niebla. Un ángel ordena a Roldán y oliveros hacer la paz, y eso hacen, intercambiándose besos de paz. Cuando Gaulthier, en Raoul de Cambrai acusa a Bernier de matar a traición a su hombre, Raoul de Cambrai, y éste admite el homicidio pero niega la traición, los dos hombres se enfrentan en un combate sin vencedor ni vencido, tras el cual el abad de Saint-Germain reconcilia a los dos adversarios. Si el resultado de un duelo

87. Beroul, Tristân.

88 La mort le roi Artu. Cuestiones semejantes se podrian plantear ante las acusaciones formuladas por: el rey Eteocles, que perjuro él mismo e hizo perjurar a los nobles que juraron a su favor (Le roman de Thebes); el desvergonzado y deshonroso Meleagant (Chretien, Lancelot); el insidioso Hardre (Ami et Amile).

89 Le roman de Thebes. Ver WHITE, «Legal Puzzles.»

90 Ver WHite, «Avoiding the Ordeal."

Hispania, LV1L/3, nu்m. 197 (1997) 957-980 
zanjado el caso de Daire el Rojo, no habría resuelto las cuestiones suscitadas por el caso, que podrían haber sido debatidas hasta el infinito; tampoco un veredicto a favor o en contra de Daire hubiera sido claramente preferible al acuerdo que, después de páginas y páginas de debate racional, finalmente se logra. En los procesos judiciales históricos del siglo XI, este tipo de avenencias son cosa corriente. Aceptar de buenas a primeras que los pactos de cualquier tipo son una auténtica expresión de acuerdo, amor y solidaridad equivale a sentimentalizarlos. Pero negar la fuerza de esta preferencia por la formalización del compromiso en las disputas intra-clase supone ignorar un rasgo fundamental de la ideologia nobiliaria. En la Francia medieval, las expresiones, a menudo hipócritas, de la solidaridad intra-clase eran también parte del juego del honor y del derecho, y siguieron siéndolo mucho después de 1215.

Los estudios anteriores sobre las escenas literarias de juicios han diagnosticado como meros problemas de prueba las auténticas cuestiones legales polémicas que plantean estos procesos ficticios $\mathrm{y}$, a continuación, han asumido que la representación de ordalías bilaterales en las narraciones vernáculas compuestas para el público laico evolucionan según unos esquemas de desarrollo basados en las evidencias sobre la actitud eclesiástica hacia las ordalías unilaterales. De esta manera, han dejado de lado continuidades significativas en la forma en que los narradores de los siglos XII y XIII construyeron sus procesos legales ficticios, los encajaron en relatos más extensos, y los utilizaron para plantear debates acerca de la lealtad, la traición, el honor y la deshonra, y no tanto sobre la probación y lo adecuado de los procedimientos judiciales tradicionales. A lo largo de los siglos XII y XIII no se detectan cambios de actitud significativos hacia el juicio por ordalía bilateral en las obras de los narradores vernáculos, la mayor parte de los cuales soslayaron totalmente las ordalías unilaterales. En los inicios de este período, los tribunales ya eran capaces de involucrarse en unos debates legales sustanciales impensables para los autores de algunos modelos del proceso de litigio altomedieval todavía influyentes; y hasta bien entrado el siglo Xw, debates prácticamente idénticos siguieron formando parte de los juicios por traición imaginarios. Sin embargo, por entonces, esta forma de "razonar" aún coexistía con una preferencia ideológica hacia el duelo como forma de resolver cuestiones de honor, hacia el empleo de avenencias y hacia un estilo de negociación legal en el que honor y vergüenza eran valores importantes.

Al interpretar de manera genérica los relatos destinados a un público aristocrático como prueba de una mutación general en la mentalité jurídica de la sociedad medieval en su conjunto, Bloch, y otros estudiosos de los plaids se arriesgaron a fabricar un "ethos legal» unitario, que se transformaba en respuesta a necesidades sociales enunciadas por los propios historiadores modernos. Así, exageraron el grado en que los nobles laicos se plegaron dócilmente a un consenso supuestamente forjado por los clérigos, los monarcas y/o la sociedad en general, acerca de cómo habra que juzgar los casos y resolver las disputas.

A lo largo de todo el período que va desde c. 1100 a c. 1250 , las principales cuestiones legales suscitadas por los juicios imaginarios por traición estaban relacionadas con el problema más amplio de cómo podían los nobles obtener honor, vengar su deshonra y negociar reclamaciones potencialmente conflictivas sobre su lealtad, y amistad efectuadas por otros nobles, incluidos los reyes. Aun- 
que los asuntos más problemáticos suscitados por los plaids imaginarios eran prácticamente imposibles de zanjar por medio de juicios basados en el resultado de combates $u$ ordalías unilaterales, la razón por la cual los tribunales fracasaban en su intento de resolverlas no era que se basasen en ordalías unilaterales o bilaterales, en vez de en otros métodos probatorios como pesquisas o juicios por jurado. De hecho, las resoluciones adoptadas por los tribunales en los procesos imaginarios se nos presentan como las mejores que era posible alcanzar, una vez que los casos habían sido remitidos a una forma de decisión, concretamente el juicio por combate, que habitualmente servía para dsignar un vencedor y un vencido y que también tenía el carácter, durante nuestro período y más adelante, de prueba legitima para probar el honor nobiliario ${ }^{91}$. Si los resultados de estos procesos son dudosos, ello no se puede achacar directamente a las deficiencias de los métodos de prueba utilizados por los tribunales imaginarios, sino más bien a la dificultad que entraña resolver, en primer lugar, los problemas de tipo jurídico y moral que los relatos pretendían suscitar y, en segundo, el problema más amplio que los narradores plantearon recurrentemente sobre cómo debían los nobles lograr el honor y evitar la deshonra.

Si se los considera como vehículos destinados a exponer la irracionalidad de las ordalías y expresar una oposición creciente tanto al combate como a las ordalías unilaterales, hay que decir que los plaids imaginarios, carecen de eficacia retórica y no incorporan claramente las preocupaciones principales que animaban el ataque clerical contra las ordalías unilaterales ${ }^{92}$. En los casos judiciales no aparecen las ordalías produciendo resultados flagrantemente injustos, y tampoco se incluyen reservas sobre la posibilidad de que se utilice las ordalías en una forma que suponga tentar a Dios.

En cambio, los plaids imaginarios compuestos de manera más artística triunfan como vehículos para explorar cuestiones polémicas en torno a la traición, la lealtad, el honor y la deshonra en una sociedad aristocrática y lo hacen en una medida que apenas puede ser oscurecida por los intentos de incorporarlos a discutibles teorías sobre el desarrollo legal medieval desde un derecho arcaico, irracional o feudal a otro moderno, racional y regio ${ }^{93}$.

Traducido por Julio Escalona Monge

\footnotetext{
91 Ver la lúcida argumentación sobre el honor y el crimen en Gauvard, «De grace especial», 1: $172-79$

92 Excepto, posiblemente, la dificultad de dar «todo su peso tanto a la confesión como a la ordalía) (Bartlett, Trial by Fire and Water, pág. 79).

93 N. del T.: La castellanización de los nombres propios de personajes de la narrativa europea medieval es siempre una cuestión problemática. En este caso el problema es mayor: por una parte, el original en inglés cita varios personajes sobradamente conocidos de los lectores españoles, como los protagonistas principales de las narraciones artúricas, o los del ciclo de Roldán, que incluso tienen un nombre propio español consolidado por el uso (Roland=Roldán, Guinevere=Ginebra, etc.); en cambio otros son mucho menos familiares y su españolización sería incluso una dificultad añadida para la comprensión del texto. Por esta razón, he preferido, siempre que fuera posible, conservar los nombres propios en la forma del original inglés, excepto en los casos en que la forma castellanizada está tan difundida que hacerlo hubjera resultado confuso. Incluso si el personaje es igualmente conocido tanto en su forma original como en la castellanizada (Lancelot=Lanzarote), he optado por la forma original.

Hispania, LVH/3, núm. 197 (1997) 957-980
} 